\title{
(9) Management of Dyspnea
}

\author{
Hiroshi Sasamoto \\ Department of Medicine, Keio University, \\ Shinano-machi, Shinjuku, Tokyo
}

Numbers of maneuvers have been reported as management of dyspneic patient among which the author would like to mention about the experimental results obtained by us from the standpoint of body temperature and metabolism, i. e. heat management against dyspneic patient, in which relatively few interest has been laid by clinical investigators.

Heat exchange in hot and cold environments:

Oxygen uptake in hot environment $\left(39^{\circ}-41^{\circ} \mathrm{C}\right.$, warm bath) increases and it decreases as the body temperature goes down in the cold environment (oxygen tent ventilated by cool compressed air of $10^{\circ}-15^{\circ} \mathrm{C}$ ), but it increases again when the rectal temperature reaches below the normal and shivering appears.

Under the condition of hot atmosphere in which the rectal temperature exceeds $38.5^{\circ} \mathrm{C}$., oxygen equivalent (necessary amount of ventilation in titers to uptake $100 \mathrm{ml}$. of oxygen) increases rapidly. This increase in oxygen equivalent might be attributed to impaired alveolar function instead of increase in dead space ventilation.

These increases in oxygen uptake and oxygen equivalent in the hot environment result in augmented ventilation and this may connect with dyspnea in high fever patient.

Heat insulation which is reciprocal of heat conductivity is small in the hot environment, while in the cold environment it becomes bigger indicating that extreme cooling of the body surface is not necessarily good maneuver to handle feveric patient.

According to the other experiment, the mechanism of change in ventilation (tidal volume and minute ventilation) in hot and cold environments is considered not due to big change in characteristics of the lung mechanics, but chiefly due to difference of tidal volume. And hence, it is reasonable to consider that the change in ventilation might be arisen by some nervous reflex.

Effect of temperature on blood gas content:

Blood oxygen content of tonometered human blood at $37^{\circ} \mathrm{C}$. and $22^{\circ} \mathrm{C}$, at $\mathrm{Po}_{2}=$ $100 \mathrm{~mm} . \mathrm{Hg}$ and $\mathrm{Po}_{2}=43 \mathrm{~mm} . \mathrm{Hg}$, respectively, is studied in vitro. Oxygen content of the blood tonometered at $22^{\circ} \mathrm{C}$. and $\mathrm{Po}_{2}=43 \mathrm{~mm}$. $\mathrm{Hg}$ increases tremendously and the difference of oxygen content between high and low $\mathrm{Po}_{2}$ blood becomes smaller. This change may be explained by the shift of oxygen dissociation curve of hemoglobin to the left, being caused by effect of low temperature. 
Similar experiment indicates increase in oxygen, especially carbon dioxide content in the blood sample at low temperature. Assuming that oxygen and carbon dioxide content in the blood at given temperature and given $\mathrm{Po}_{2}$ and $\mathrm{Pco}_{2}$ represents efficiency of transportation of blood gases, it is not unreasonable to consider that increase in oxygen and carbon dioxide content in the blood at low temperature indicates one possibility of improving oxygen and carbon dioxide balance at the site of tissue by making body temperature cool. This may suggest one of the mechanisms of relieving dyspnea, but we need further in vivo experiment in the future to give definite answers in this respect.

Practical measures to manage heat:

From the clinical point of view, practical ways to handle heat with the idea of relieving dyspneic patient are as follows; adjustment of environmental temperature and clothing, bed etc., utilization of oxygen tent being ventilated by cold air or oxygen at $12^{\circ}-18^{\circ} \mathrm{C}$., taking cold drinks and foods and so on. It is necessary to remember that we must try to keep the "body core" at low temperature, not outside of the body surface. 